\title{
Antifungal activity of propolis against Candida species isolated from cases of chronic periodontitis
}

\section{Ana Beatriz Sotero SIQUEIRA ${ }^{(a)}$ Larissa Rodrigues Nolasco de Araújo RODRIGUEZ(b) \\ Ruth Karine Barroso SANTOS(b) \\ Ricardo Romulo Batista MARINHO(c) \\ Sheila ABREU(d) \\ Raniel Fernandes PEIXOTO(e) \\ Bruno César de Vasconcelos GURGEL (f)}

(a) Universidade Federal de Pernambuco - UFPE, Centro de Ciências da Saúde, Department of Pharmaceutical Sciences, Recife, PE, Brazil.

(b) Centro Universitário Cesmac, Curso de Biomedicina, Maceió, AL, Brazil.

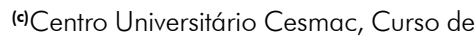
Odontologia, Maceió, AL, Brazil.

(d)Pharma Néctar ${ }^{\circledR}$, Belo Horizonte, MG, Brazil.

(e) Universidade de São Paulo - USP, Ribeirão Preto School of Dentistry, Department of Dental Materials and Prosthodontics, Ribeirão Preto, SP, Brazil.

(f) Universidade Federal do Rio Grande do Norte - UFRN, Centro de Ciências da Saúde, Department of Dentistry, Natal, RN, Brazil.

Declaration of Interests: The authors certify that they have no commercial or associative interest that represents a conflict of interest in connection with the manuscript.

Corresponding Author:

Ana Beatriz Soteiro Siqueira

E-mail: absiqueira@hotmail.com

DOI: 10.1590/1807-3107BOR-2015.vol29.0083

Submitted: Nov 20, 2014

Accepted for publication: Mar 14, 2015

Last revision: May 27, 2015
Abstract: This research evaluated the fungistatic and fungicidal activities of red propolis alcoholic extract (RPAE) against different Candida species isolated from chronic periodontitis cases, and compared with chlorhexidine (CHX). Nineteen samples of Candida species (C. albicans $[\mathrm{n}=12]$, C. tropicalis $[\mathrm{n}=5]$ and C. glabrata $[\mathrm{n}=2])$ isolated from chronic periodontitis cases were analyzed. The fungistatic and fungicidal activity of both RPAE and CHX were evaluated using fluconazole and C. parapsilosis (ATCC 6258) as a control. Fungistatic activity was analyzed based on the Clinical and Laboratory Standards Institute (CLSI) reference procedure to determine the minimum inhibitory concentrations. Fungicidal activity was established according to the absence of fungal growth on Sabouraud Dextrose Agar medium. The fungistatic and fungicidal activities of RPAE were observed, respectively, at 32-64 $\mu \mathrm{g} / \mathrm{mL}$ and $64-512 \mu \mathrm{g} / \mathrm{mL}$ for C. albicans, $64 \mu \mathrm{g} / \mathrm{mL}$ and $64-256 \mu \mathrm{g} / \mathrm{mL}$ for C. glabrata, and 32-64 $\mu \mathrm{g} / \mathrm{mL}$ and $64 \mu \mathrm{g} / \mathrm{mL}$ for C. tropicalis. CHX fungistatic activity was observed at concentrations of $0.003-1.92 \mu \mathrm{g} / \mathrm{mL}$ for C. albicans, $1.92 \mu \mathrm{g} / \mathrm{mL}$ for C. glabrata, and $0.03-1.92 \mu \mathrm{g} / \mathrm{mL}$ for $C$. tropicalis. Fluconazole fungistatic activity ranged between 1-64 $\mu \mathrm{g} / \mathrm{mL}$, and fungicidal activity occurred at 8-64 $\mu \mathrm{g} / \mathrm{mL}$, for the three Candida species analyzed. All the Candida species were susceptible to RPAE antifungal activity, but five samples of C. albicans, one of C. tropicalis and one of C. glabrata were resistant to fluconazole antifungal activity. CHX showed fungistatic activity against all the Candida species analyzed. The antifungal potential of these substances suggests that they can be applied as an alternative treatment for diseases affected by these species.

Keywords: Candida; Propolis; Chlorhexidine; Periodontitis.

\section{Introduction}

The presence of fungi, bacteria and viruses in dental biofilm can contribute to the progression of periodontal disease. Some authors have reported the prevalence of bacteria associated with periodontitis, ${ }^{1}$ but other studies have related the presence of fungi such as Candida. These fungi form part of an individual's microbiota, especially in areas of the mucosa, such as the oral cavity, and play an important role both in health and in the development of oral diseases. ${ }^{2}$ 
Subgingival colonization by C. albicans, C. dubliniensis, C. glabrata and C. tropicalis has been described by other authors. ${ }^{3}$ Tamai et al. ${ }^{2}$ found that C. albicans may boost the infectious effect of periodontitis by acting in conjunction with anaerobic bacteria. Individuals susceptible to primary infection have been reported to use an antifungal prophylaxis to prevent cases of recurrence. ${ }^{4}$ Among the different chemical agents used, chlorhexidine has broad-spectrum antiseptic action. It is used in maintaining periodontal therapy, and as a treatment adjuvant in scaling and root planing procedures. ${ }^{5}$ The fungistatic activity of $0.12 \%$ chlorhexidine has also been reported as preventing the growth of $C$. albicans on denture acrylic resin. ${ }^{6}$

The antimicrobial activities of natural derivatives, such as propolis, have been researched over recent years as alternatives for new therapeutic strategies. The presence of flavonoids, as well as phenolic, aromatic and diterpene acids, in the composition of propolis, has been associated with various biological attributes, including its antifungal properties. ${ }^{7,8}$

The antifungal activity of Brazilian red propolis against different Candida species has already been reported in the literature. ${ }^{7,89}$ This propolis variety is obtained from exudates collected by bees (Apis mellifera) from the surface of Dalbergia ecastophyllum in the Northeast of Brazil, and contains a high concentration of flavonoids. ${ }^{10}$ The antifungal activity of this red propolis (from Paraiba State, Brazil) proved effective against Trichophyton tonsurans, T. rubrum and T. mentagrophytes,; however, the present study is the first to investigate the antifungal activity of red propolis against Candida species isolated from periodontal pockets.

The chemical composition of red propolis alcoholic extract indicates a predominance of flavonoids, such as rutin, liquiritigenin, daidzein, pinobanksin, quercetin, luteolin, dalbergin, isoliquiritigenin, pinocembrin, pinobanksin-3-acetate, biochanin A and formononetin, the last being the predominant component. ${ }^{10}$

Thus, the aim of this study was to evaluate the in vitro fungistatic and fungicidal activities of Brazilian red propolis alcoholic extract against the Candida species isolated from cases of periodontitis. Its effects were compared with those of chlorhexidine, an agent considered the gold standard for antifungal periodontal treatment.

\section{Methodology}

\section{Fungi samples}

Candida samples (twelve isolates of C. albicans [63\%], five of C. tropicalis [26\%] and two of C. glabrata [11\%]) were obtained from periodontal pockets of patients with chronic periodontitis seen in the Faculdade de Odontologia of the Centro Universitário Cesmac [Clinical Dental School of the Cesmac University Center]. All isolates were preserved in mineral oil ${ }^{12}$ taxonomically confirmed, and then seeded on CHROMagar Candida ${ }^{\circledR}$ (BD, Sao Paulo, Brazil) in a Petri dish kept at $37^{\circ} \mathrm{C}$ for 48 h. $^{13}$ A sample of C. parapsilosis (ATCC 6258) was used as the control.

This study was approved by the Research Ethics Committee of Centro Universitário Cesmac, Alagoas, Brazil (protocol number: 723/09).

\section{Evaluation of antifungal activity}

The antifungal agents evaluated were fluconazole (Pfizer ${ }^{\circledR}$, Sao Paulo, Brazil), chlorhexidine and red propolis alcoholic extract (lot code PRDE0906 - Pharmanéctar ${ }^{\circledR}$, Belo Horizonte, Brazil). According to the certificate of analysis provided by the manufacturer of the red propolis alcoholic extract, the chemical composition of the product is consistent with that found by Daugsch et al. ${ }^{10}$ The procedure was performed according to standards published in document M27-A3 by the Clinical and Laboratory Standards Institute (CLSI). ${ }^{14}$ The culture medium used was bicarbonate-free RPMI 1640 (Sigma-Aldrich, St. Louis, USA) with L-glutamine, buffered to $\mathrm{pH}$ 7.0 with $0.165 \mathrm{M}$ morpholinepropanesulfonic acid (MOPS) (Sigma-Aldrich, St. Louis, USA). The medium was sterilized by filtration through a 0.22 $\mu \mathrm{m}$ Millipore membrane.

The commercial antifungal agent was dissolved in sterile distilled water and prepared in concentrations ranging from 0.125 to $64 \mu \mathrm{g} / \mathrm{mL}$. The lyophilized red propolis alcoholic extract, originally from Paraiba (Brazil's Northeast region), was solubilized in $70 \%$ ethyl alcohol (v/v), according to Sawaya et al., ${ }^{8}$ to obtain concentrations from of 4 to $2048 \mu \mathrm{g} / \mathrm{mL}$. Chlorhexidine was prepared at concentrations from 0.003 to $1.92 \mu \mathrm{g} / \mathrm{mL}$, corresponding to 0.000003 and $0.000192 \%$, respectively. 
All Candida isolates were plated on Sabouraud Dextrose Agar medium contained in test tubes and maintained at $28^{\circ} \mathrm{C}\left( \pm 1^{\circ} \mathrm{C}\right)$, for $48 \mathrm{~h}$, to standardize the inoculum. Thereafter, suspensions were prepared in $5 \mathrm{ml}$ of $0.145 \mathrm{~mol} / \mathrm{L}$ sterile saline solution, then vortexed for 15 seconds. The cell density was adjusted to an equivalent of 0.5 on the McFarland scale and standardized in a spectrophotometer at $530 \mathrm{~nm}$ to obtain $90 \%$ transmittance. The suspensions were then diluted sequentially in a RPMI 1640 liquid medium to obtain concentrations of 1:100 to $1: 20$, resulting in a concentration of $2-5 \times 10^{3}$ cells $/ \mathrm{mL}$.

Sterile microtiter plates (TPP, Trasandingen, Switzerland) containing 96 U-wells were used to perform the test procedure. $100 \mu \mathrm{L}$ of fluconazole, red propolis and chlorhexidine were deposited on separate plates, in rows from 1 to 10 , and each concentration was deposited in a row. $100 \mu \mathrm{L}$ of RPMI 1640 medium was deposited in well rows 11 and 12, in which the controls and the sterilization medium were grown, respectively. These plates were stored at $-20^{\circ} \mathrm{C}$ until use.

At test time, $100 \mu \mathrm{L}$ of standardized inoculum was deposited in each well, and the microtiter plates were incubated at room temperature $\left(28 \pm 1^{\circ} \mathrm{C}\right)$ for $48 \mathrm{~h}$ until the interpretation of the results. The determination of the minimum inhibitory concentrations (MIC) of fluconazole, red propolis and chlorhexidine was performed by visual observation of each well to identify the reduction in fungal growth. Considering the total growth $(100 \%)$ in the control well, the percentage growth reduction was attributed to the remaining wells.

The MIC for fluconazole was regarded as the lowest concentration, inhibiting growth by $\geq 50 \%$. The interpretive CLSI breakpoints for fluconazole were: susceptible [S]: $\leq 8 \mu \mathrm{g} / \mathrm{mL}$; susceptible dose dependent [SDD]: from 16 to $32 \mu \mathrm{g} / \mathrm{mL}$; and resistant $[\mathrm{R}]: \geq 64 \mu \mathrm{g} / \mathrm{mL}$. The MICs for chlorhexidine and red propolis were regarded as the lowest concentrations, inhibiting fungal growth by $100 \%$.

The minimum fungicidal concentration (MFC) was determined as follows: the contents of the wells showing $100 \%$ inhibition of fungal growth were transferred from the microtiter plate to Petri dishes containing Sabouraud Dextrose Agar medium. The dishes were kept at room temperature $\left(28 \pm 1^{\circ} \mathrm{C}\right)$ for $72 \mathrm{~h}$ to determine the development of Candida colonies. The MFC corresponded to the lowest fungistatic concentration preventing fungal grow th. ${ }^{15}$ The MIC and MFC of fluconazole, red propolis and chlorhexidine were determined, as well as the concentration capable of inhibiting either half or all of the fungal growth ( $\mathrm{MIC}_{50}$ and $\mathrm{MIC}_{100}$, respectively).

\section{Results}

All the samples of $C$. albicans, C. tropicalis and C. glabrata were confirmed in regard to aspects of purification and taxonomy. No fungistatic activity of fluconazole was observed for any isolate of any species analyzed; for this reason, these results are not shown in Table 1. Sensitivity to fluconazole was observed

Table 1. Mean results of fungistatic activity of fluconazole, red propolis alcoholic extract and chlorhexidine against Candida species isolated from cases of chronic periodontitis.

\begin{tabular}{|c|c|c|c|c|}
\hline Candida species (number of samples tested) & Antifungal (growth inhibition) & $M I C s^{a}(\mu \mathrm{g} / \mathrm{mL})$ & $\mathrm{MIC}_{50}{ }^{\mathrm{b}}(\mu \mathrm{g} / \mathrm{mL})$ & $\mathrm{MIC}_{100}{ }^{c}(\mu \mathrm{g} / \mathrm{mL})$ \\
\hline \multirow[t]{3}{*}{ Candida albicans (11) } & Fluconazole & $1-32$ & 4 & 32 \\
\hline & Red propolis & $32-64$ & 32 & 64 \\
\hline & Chlorhexidine & $0.003-1.92$ & 0.12 & 1.92 \\
\hline \multirow[t]{3}{*}{ Candida glabrata (1) } & Fluconazole & 2 & $N D^{d}$ & 2 \\
\hline & Red propolis & 64 & 64 & 64 \\
\hline & Chlorhexidine & 1.92 & 1.92 & 1.92 \\
\hline \multirow[t]{3}{*}{ Candida tropicalis (4) } & Fluconazole & $1-8$ & 1 & 8 \\
\hline & Red propolis & $32-64$ & 64 & 64 \\
\hline & Chlorhexidine & $0.003-1.92$ & 0.48 & 1.92 \\
\hline
\end{tabular}

a MIC: Minimum Inhibitory Concentration

${ }^{\mathrm{b}} \mathrm{MIC}_{50}$ : Minimum inhibitory concentration able to inhibit $50 \%$ of the C. albicans, C. glabrata and C. tropicalis samples.

${ }^{-} \mathrm{MIC}_{100}$ : Minimum inhibitory concentration able to inhibit $100 \%$ of the C. albicans, C. glabrata and C. tropicalis samples.

${ }^{\mathrm{N}} \mathrm{ND}$ : Not determined 
in nine isolates of $C$. albicans, four of $C$. tropicalis and one of $C$. glabrata (MIC $\leq 8 \mu \mathrm{g} / \mathrm{mL}$ ). Two isolates of C. albicans were SDD, demonstrating MICs of 16 and $32 \mu \mathrm{g} / \mathrm{mL}$. In addition, five samples of $C$. albicans, one of $C$. tropicalis and one of $C$. glabrata were resistant to the fungicidal activity of fluconazole.

The fungistatic activity of chlorhexidine was observed in concentrations of $0.003-1.92 \mu \mathrm{g} / \mathrm{mL}$, $1.92 \mu \mathrm{g} / \mathrm{mL}$ and $0.03-1.92 \mu \mathrm{g} / \mathrm{mL}$ for C. albicans, C. glabrata and C. tropicalis, respectively.

The fungistatic activity of red propolis alcoholic extract was 32-64 $\mu \mathrm{g} / \mathrm{mL}$ for C. albicans, $64 \mu \mathrm{g} / \mathrm{mL}$ for C. glabrata and $32-64 \mu \mathrm{g} / \mathrm{mL}$ for $C$. tropicalis. The fungicidal activity was $64-512 \mu \mathrm{g} / \mathrm{mL}$ for C. albicans, $64-256 \mu \mathrm{g} / \mathrm{mL}$ for C. tropicalis, and $64 \mu \mathrm{g} / \mathrm{mL}$ for C. glabrata.

The fungicidal activity of red propolis alcoholic extract and of chlorhexidine was observed for all Candida species. tested. The MFC was $0.003 \mu \mathrm{g} / \mathrm{mL}$ for chlorhexidine. The results are shown in Tables 1 and 2.

\section{Discussion}

The frequency rates of $C$. albicans, C. tropicalis and C. glabrata in oral infections have been previously reported by other authors, who confirmed the susceptibility of the Candida species associated with chronic periodontitis to fluconazole. ${ }^{16}$ Similar results were observed in the present study.

The variation in the MICs obtained for fluconazole for samples of $C$. albicans $(\geq 64 \mu \mathrm{g} / \mathrm{mL}$, and a resistance profile) have been previously reported by other authors. ${ }^{17}$ The decrease in the susceptibility profiles of non-albicans samples to fluconazole may be attributed to this antifungal agent, used both prophylactically and as a treatment. A national survey in Taiwan showed increasing rates of fluconazole resistance, from $1.9 \%$ in 2002 to $17.1 \%$ in 2006 , mainly among non-blood or non-albicans isolates. ${ }^{18}$

A similar susceptibility of C. albicans to Brazilian red propolis alcoholic extract in different concentrations $(32-512 \mu \mathrm{g} / \mathrm{mL})$ was observed in this study for C. albicans to Mexican propolis (at higher concentrations of 0.06 to $32 \mathrm{mg} / \mathrm{mL}){ }^{19}$ unlike the susceptibility of $C$. glabrata to Iranian propolis (approximately $5000 \mu \mathrm{g} / \mathrm{mL})^{20}$ and of $C$. tropicalis to Chilean propolis $(197-476 \mu \mathrm{g} / \mathrm{mL}){ }^{21}$

Sforcin et al. ${ }^{22}$ reported that $C$. albicans was more susceptible to propolis from Sao Paulo (Brazil) than C. tropicalis. Our results were similar for $\mathrm{MIC}_{50}$; however, in regard to fungicidal activity, the susceptibility of C. tropicalis was higher. The antifungal effect of Brazilian propolis from the northeastern region, as observed in this study, is consistent with the findings of other studies that used Brazilian propolis from the southeastern region; however, the antifungal activity was observed at higher concentrations for the propolis from the Southeast of Brazil (between 3 and $12 \mu \mathrm{g} / \mathrm{mL}){ }^{23}$

Most biological activities of propolis are related to the alcoholic extract, because when the extract is prepared in ethyl alcohol, a greater amount of active compounds are extracted and the inhibitory effect is greater. ${ }^{24}$ When water is used as the solvent, the antifungal and antibacterial activities are weaker, compared with the alcoholic extract. ${ }^{8}$

Table 2. Mean results of fungicidal activity of fluconazole and red propolis alcoholic extract against Candida species isolated from cases of chronic periodontitis.

\begin{tabular}{|c|c|c|c|c|}
\hline Candida species (number of samples tested) & Antifungal (growth inhibition) & $M F C s^{\circ}\left(\mu \mathrm{g} / \mathrm{mL}^{-1}\right)$ & $\mathrm{MFC}_{50} \mathrm{~b}\left(\mu \mathrm{g} / \mathrm{mL}^{-1}\right)$ & $\mathrm{MFC}_{100^{c}}\left(\mu \mathrm{g} / \mathrm{mL}^{-1}\right)$ \\
\hline \multirow[t]{2}{*}{ Candida albicans (12) } & Fluconazole & $8-64$ & 32 & $N D^{d}$ \\
\hline & Red propolis & $64-512$ & ND & 512 \\
\hline \multirow[t]{2}{*}{ Candida glabrata (5) } & Fluconazole & $8-32$ & 16 & ND \\
\hline & Red propolis & $64-256$ & ND & 256 \\
\hline \multirow[t]{2}{*}{ Candida tropicalis (2) } & Fluconazole & 64 & 64 & ND \\
\hline & Red propolis & 64 & ND & 64 \\
\hline
\end{tabular}

a MFC: Minimum Fungicidal Concentration

${ }^{b} \mathrm{MFC}_{50}$ : Minimum fungicidal concentration able to inhibit $50 \%$ of the C. albicans, C. glabrata and C. tropicalis samples.

cMFC ${ }_{100}$ : Minimum fungicidal concentration able to inhibit 100\% of the C. albicans, C. glabrata and C. tropicalis samples.

${ }^{d}$ ND: Not determined 
Flavonoids are largely responsible for antifungal activity. ${ }^{9,10}$ The susceptibility of different Candida species is dependent on the chemical composition of the propolis; however, Sforcin et al..$^{22}$ found no change in the susceptibility of $C$. albicans and C. tropicalis. Thus, the fungicidal activity of red propolis alcoholic extract found in this study could be attributed to its chemical composition. ${ }^{25}$

The use of propolis in dentistry has been proposed as an aid in the treatment of oral infections. Koo et al. $^{26}$ evaluated the antimicrobial activity of red propolis alcoholic extract from Minas Gerais, southeastern Brazil (10\% w/v) and concluded that propolis may have an effect on periodontal disease, because of its antifungal activity against $C$. albicans and other microorganisms, and because it inhibits the formation of biofilm in vitro.

Chlorhexidine is known to have excellent antifungal activity in vitro against all isolates of C. albicans, C. glabrata and C. tropicalis. Furthermore, fungistatic and fungicidal activities were found at a concentration of $1.92 \mu \mathrm{g} / \mathrm{mL}$. Dodwad and Kukreja ${ }^{27}$ found that chlorhexidine $(0.2 \%)$ can inhibit dental biofilm formation better than propolis contained in mouthwash solutions. The fungistatic activity

\section{References}

1. Ferreira FB, Torres SA, Rosa OP, Ferreira CM, Garcia RB, Marcucci MC, et al. Antimicrobial effect of propolis and other substances against selected endodontic pathogens. Oral Surg Oral Med Oral Pathol Oral Radiol Endod. 2007 Nov;104(5):709-16.

2. Tamai R, Sugamata M, Kiyoura Y. Candida albicans enhances invasion of human gingival epithelial cells and gingival fibroblasts by Porphyromonas gingivalis. Microb Pathog. 2011 Oct;51(4):250-4.

3. Pizzo G, Barchiesi F, Falconi Di Francesco L, Giuliana G, Arzeni D, Milici ME, et al. Genotyping and antifungal susceptibility of human subgingival Candida albicans isolates. Arch Oral Biol. 2002 Mar;47(3):189-96.

4. Azevedo RVP, Komesu MC, Candido RC, Salvetti C, Rezende FHC. Candida sp in the oral cavity with and without lesions: maximal inhibitory dilution of propolis and Periogard. Rev Microbiol. 1999 Oct-Dec;30(4):335-41.

5. Guarnelli ME, Franceschetti G, Manfrini R, Trombelli L. Adjunctive effect of chlorhexidine in ultrasonic of chlorhexidine has also been reported recently in the literature. Whereas the $\mathrm{MIC}_{90}$ for different Candida species, including C. albicans, C. glabrata and C. parapsilosis, was $6.25 \mathrm{mg} / \mathrm{L}^{28}$ our results showed an activity of $1.92 \mu \mathrm{g} / \mathrm{mL}$. Ellepola et al. ${ }^{29}$ found that chlorhexidine interferes with the formation of the germ tube of $C$. albicans, in subtherapeutic concentrations $(0.00125,0.0025$ and $0.005 \%)$. According to Pizzo et al., ${ }^{30}$ chlorhexidine causes changes in the epithelial cell surface of the oral mucosa, thus interfering in the colonization of different Candida species, and indicating a reduction in the adhesion of these fungi.

\section{Conclusion}

The results of this study show that, similar to chlorhexidine, red propolis alcoholic extract has good fungistatic and fungicidal activity against most samples of Candida species. This antifungal activity may hold a promise for future applications as an alternative treatment for infections caused by these fungi. Further investigation into the use of red propolis for the prevention and treatment of periodontal diseases is required, including microbiological, randomized controlled trials and longitudinal studies.

instrumentation of aggressive periodontitis patients: a pilot study. J Clin Periodontol. 2008 Apr;35(4):333-41.

6. Pusateri CR, Monaco EA, Edgerton M. Sensitivity of Candida albicans biofilm cells grown on denture acrylic to antifungal proteins and chlorhexidine. Arch Oral Biol. 2009 Jun;54(6):588-94.

7. Oliveira AC, Shinobu CS, Longhini R, Franco SL, Svidzinski TI. Antifungal activity of propolis extract against yeasts isolated from onychomycosis lesions. Mem Inst Oswaldo Cruz. 2006 Aug;101(5):493-7.

8. Sawaya AC, Palma AM, Caetano FM, Marcucci MC, Cunha IBS, Araujo CE, et al. Comparative study of in vitro methods used to analyse the activity of propolis extracts with different compositions against species of Candida. Lett Appl Microbiol. 2002 Sep;35(3):203-7.

9. Trusheva B, Popova M, Bankova V, Simova S, Marcucci MC, Miorin PL, et al. Bioactive constituents of brazilian red propolis. Evid Based Complement Alternat Med. 2006 Jun;3(2):249-54. 
10. Daugsch A, Moraes CS, Fort P, Park YK. Brazilian red propolis--chemical composition and botanical origin. Evid Based Complement Alternat Med. 2008 Dec;5(4):435-41.

11. Siqueira AB, Gomes BS, Cambuim I, Maia R, Abreu S, Souza-Motta CM, et al. Trichophyton species susceptibility to green and red propolis from Brazil. Lett Appl Microbiol. 2009 Jan;48(1):90-6.

12. Sherf A. A method for maintaining Phytomonas sepedomica for long periods without transfer. Phytopathology. 1943;31:30-2.

13. Yucesoy M, Marol S. Performance of CHROMAGAR candida and BIGGY agar for identification of yeast species. Ann Clin Microbiol Antimicrob. 2003 Oct;2:8. doi: 10.1186/1476-0711-2-8.

14. Clinical and Laboratory Standards Institute (CLSI). Reference method for broth dilution testing of yeasts. Approved standard document M27-A3. Wayne (PA): CLSI; 2008.

15. Favre B, Hofbauer B, Hildering KS, Ryder NS. Comparison of in vitro activities of 17 antifungal drugs against a panel of 20 Dermatophytes by using a microdilution assay. J Clin Microbiol. 2003 Oct;41(10):4817-9.

16. Furlletti VF, Mardegan RC, Obando-Pereda GA, Aníbal PC, Duarte MCT, Gonçalves RB, et al. Susceptibility of Candida spp. oral isolates for azolic antifungals and amphotericin B. Braz J Oral Sci. 2008 Apr-Jun;7(25):1543-9.

17. Koga-Ito CY, Komiyama EY, Martins CAP, Santos SSF, Balducci I, Jorge AOC. Phenotypic characterization of Candida spp. isolates from chronic periodontitis patients Brazilian. Braz J Oral Sci. 2008 Apr-Jun;7(25):1531-4.

18. Yang YL, Wang AH, Wang CW, Cheng WT, Li SY, Lo HJ, et al. Susceptibilities to amphotericin B and fluconazole of Candida species in Taiwan Surveillance of Antimicrobial Resistance of Yeasts 2006. Diagn Microbiol Infect Dis. 2008 Jun;61(2):175-80.

19. Quintero-Mora ML, Londono-Orozco A, Hernandez-Hernandez F, Manzano-Gayosso P, Lopez-Martinez R, Soto-Zarate CI, et al. Effect of Mexican propolis extracts from Apis mellifera on Candida albicans in vitro growth. Rev Iberoam Micol. 2008 Mar;25(1):22-6. Spanish.

20. Shokri H, Khosravi AR, Yalfani R. Antifungal efficacy of propolis against fluconazole-resistant Candida glabrata isolates obtained from women with recurrent vulvovaginal candidiasis. Int J Gynaecol Obstet. 2011 Aug;114(2):158-9.

21. Herrera CL, Alvear M, Barrientos L, Montenegro G, Salazar LA. The antifungal effect of six commercial extracts of Chilean propolis on Candida spp. Cien Inv Agr. 2010 Abr;37(1):75-84.

22. Sforcin JM, Fernandes-Júnior A, Lopes CAM, Funari SRC, Bankova V. Seasonal effect of brazilian propolis on Candida albicans and Candida tropicalis. J Venom Anim Toxins. 2001;7:139-44.

23. Ota C, Unterkircher C, Fantinato V, Shimizu MT. Antifungal activity of propolis on different species of Candida. Mycoses. 2001 Nov;44(9-10):375-8.

24. Agüero MB, Svetaz L, Baroni V, Lima B, Luna L, Zacchino $\mathrm{S}$, et al. Urban propolis from San Juan province (Argentina): Ethnopharmacological uses and antifungal activity against Candida and dermatophytes. Ind Crops Prod. 2014 Jun;57:166-73. doi: 10.1016/j.indcrop.2014.03.009.

25. Mello BCBS, Petrus JCC, Hubinger MD. Concentration of flavonoids and phenolic compounds in aqueous and ethanolic propolis extracts through nanofiltration. J Food Eng. 2010 Feb;96(4):533-9.

26. Koo H, Gomes BP, Rosalen PL, Ambrosano GM, Park YK, Cury JA. In vitro antimicrobial activity of propolis and Arnica montana against oral pathogens. Arch Oral Biol. 2000 Feb;45(2):141-8.

27. Dodwad V, Kukreja BJ. Propolis mouthwash: a new beginning. J Indian Soc Periodontol. 2011 Apr;15(2):121-5.

28. Salim N, Moore C, Silikas N, Satterthwaite J, Rautemaa R. Chlorhexidine is a highly effective topical broad-spectrum agent against Candida spp. Int J Antimicrob Agents. 2013 Jan;41(1):65-9.

29. Ellepola AN, Joseph BJ, Khan ZU. Effects of subtherapeutic concentrations of chlorhexidine gluconate on germ tube formation of oral Candida. Med Princ Pract. 2012;21(2):120-4.

30. Pizzo G, Giuliana G, Milici ME, D’Angelo M. Effect of antimicrobial mouthrinses on the in vitro adhesion of Candida albicans to human buccal epithelial cells. Clin Oral Investig. 2001 Sep;5(3):172-6. 